\title{
An in vitro Comparative Study to evaluate the Marginal Fit of Castings using Ring and Ringless Casting Techniques with varying Sprue Diameter
}

\author{
${ }^{1}$ Tanuka Dutta, ${ }^{2}$ Vinu Thomas George, ${ }^{3}$ Dhanasekar Balakrishnan, ${ }^{4}$ Aparna Ichalangod Narayan
}

\begin{abstract}
Introduction: The ultimate success of fixed prosthesis is to pay meticulous attention to the detailed production of the missing tooth structure. Such an accurate replication is technically demanding. Hence, the aim of the study was to evaluate the accuracy of marginal fit of castings with varying sprue diameter and using ring and ringless techniques.
\end{abstract}

Materials and methods: Forty standardized wax copings were fabricated on a stainless steel die and divided into two groups. The first group was cast using the metal ring investment technique; the second group was cast using the ringless investment technique. Both the groups were further divided into two groups, each based on the diameter of the sprue (groups I and III: $4.5 \mathrm{~mm}$ and groups II and IV: $2.5 \mathrm{~mm}$ ). The vertical marginal gap was measured at three sites per specimen, using a digital optical microscope at $\times 100$ magnification. The results were analyzed using two-way analysis of variance and independent t-test to determine statistical significance.

Results: The vertical marginal gaps of castings fabricated using the ringless technique $(0.145 \pm 0.072 \mathrm{~mm})$ were significantly less $(p<0.001)$ than those castings fabricated using the conventional metal ring technique $(0.264 \pm 0.100 \mathrm{~mm})$; however, the vertical marginal gaps of the $2.5 \mathrm{~mm}$ sprue diameter $(0.199$ $\pm 0.092 \mathrm{~mm})$ and $4.5 \mathrm{~mm}$ sprue diameter $(0.211 \pm 0.118 \mathrm{~mm})$ castings were not statistically significant $(p>0.05)$. There was also statistically significant interaction $(p<0.001)$ between group IIA $(0.120 \pm 0.038 \mathrm{~mm})$ and group IA $(0.302 \pm 0.098 \mathrm{~mm})$, which was analyzed using the independent t-test.

Conclusion: It can be concluded that the ringless casting technique in comparison to metal ring technique produces metal castings of better marginal adaptation. Furthermore, the sprue diameter had significant difference wherein the 4.5 $\mathrm{mm}$ diameter produced the least vertical discrepancies in the ringless casting technique and $2.5 \mathrm{~mm}$ produced lesser vertical discrepancies in the metal ring.

Clinical significance: One of the key factors that decides the success of a metal-ceramic restoration is the marginal fit. The accurate fit of the restoration greatly minimizes the plaque accumulation, offers good mechanical properties, and reduces micro-

\footnotetext{
${ }^{1-4}$ Department of Prosthodontics and Crown \& Bridge, Manipal College of Dental Sciences, Manipal University, Manipal Karnataka, India

Corresponding Author: Vinu Thomas George, Department of Prosthodontics and Crown \& Bridge, Manipal College of Dental Sciences, Manipal University, Manipal, Karnataka, India, e-mail: drvgeorge@gmail.com
}

leakage and development of secondary caries. The techniques of casting procedure and sprue diameter can have an influence on the outcome. Hence, the current research was undertaken to study the influence of these factors on marginal fit.

Keywords: Marginal fit, Metal castings, Ring and ringless techniques, Sprue diameter.

How to cite this article: Dutta T, George VT, Balakrishnan D, Narayan Al. An in vitro Comparative Study to evaluate the Marginal Fit of Castings using Ring and Ringless Casting Techniques with Varying Sprue Diameter. World J Dent 2017;8(2):109-113.

Source of support: Nil

Conflict of interest: None

\section{INTRODUCTION}

The long-term success of metal ceramic restorations among all other factors relies chiefly on minimizing the marginal gap at the finish line. ${ }^{1}$ The very importance of accurate fit of dental castings is that it allows less plaque accumulation, offers better mechanical properties, decreases the cement space, hence, less chances for microleakage and secondary caries development. Therefore, there has been every effort expended in the field of fixed prosthodontics to achieve a restoration of precise fit through means of strict and controlled steps in the process of casting. ${ }^{2-4}$

The variables in the process of casting that affects the final restoration are materials creating the crown patterns, alloy-investment combination, sprue material and its geometry, alloy combinations, casting method, casting temperature, and casting techniques. ${ }^{5-7}$

Conventionally, the metal ring has been used for investing and casting of dental prosthesis. However, research indicates that the use of metal ring tends to restrict the thermal expansion of the investment material leading to the forces exerted inward leading to undersized restorations. ${ }^{8}$ In addition, the use of a wet ring liner aids for more expansion but to some extent. ${ }^{9,10}$ Moreover, the expansion of metal ring is less than the investment, which further limits the thermal expansion of the investment material. ${ }^{11,12}$ This technique was consequently challenged with an alternative technique of ringless casting system that permits unrestricted expansion of the investment due 
to removal of the ring. The procedure consists of a plastic ring that confines the heat-resistant phosphate bonded investment to allow its initial setting followed by removal of the plastic ring to permit an isotropic expansion of the investment material. ${ }^{13,14}$

Another factor that affects success of casting is the sprue that forms a channel through which the molten metal can flow and fill the mold space. The efficacy of the sprue design depends on various components, such as the thickness of the sprue, sprue angulation to the wax pattern, material of the sprue, and location of the sprue. Above all, sprue diameter plays a vital role. Preferably, various authors have recommended that the sprue thickness should be same or larger than the thickest portion of the wax pattern. ${ }^{15,16}$

Hence, the purpose of this in vitro study was to evaluate the marginal fit of metal castings using metal ring and ringless casting techniques and to find out a reliable technique which can be used for routine casting. The study also reflects on the effect of sprue diameter on the marginal discrepancy of the metal castings.

\section{MATERIALS AND METHODS}

A standardized stainless steel metal die with a core of $6 \mathrm{~mm}$ height and $8 \mathrm{~mm}$ diameter, with $6^{\circ}$ taper and a $1.5 \mathrm{~mm}$ uniform sharp cervical margin of $90^{\circ}$ was made to simulate a prepared molar tooth on which the wax patterns were fabricated. To ensure uniform thickness of the wax pattern, a stainless steel analog with no superior surface was also made that fits exactly onto the metal die creating a uniform space of $1.5 \mathrm{~mm}$. Predetermined markings were scribed on the master die at three points at the level of the finish line to identify the marginal discrepancies. ${ }^{17,18}$

On the metal die, 40 wax patterns were fabricated, which was divided into two groups: The metal ring casting and ringless casting group with 20 metal copings each. The metal ring casting and ringless casting groups were further subdivided based on the sprue diameter into two groups: Groups I and III $(4.5 \mathrm{~mm})$ and groups II and IV (2.5 mm) (Table 1).

To fabricate the cylindrical wax pattern, the stainless steel analog and the die were first brushed with the die lubricant. The crown blue wax was melted over the burner, which was poured into the space between the analog and the metal die from the superior opening. The assembly was held together for 3 minutes to allow the wax to completely harden.

Table 1: Study groups

\begin{tabular}{lllll}
\hline Groups & Group I & Group II & Group III & Group IV \\
\hline Type of ring & Ring & Ring & Ringless & Ringless \\
Sprue diameter & $4.5 \mathrm{~mm}$ & $2.5 \mathrm{~mm}$ & $4.5 \mathrm{~mm}$ & $2.5 \mathrm{~mm}$ \\
\hline
\end{tabular}

This was followed by spruing of each wax pattern with the respective sprue diameters. The wax patterns belonging to groups I and III were sprued with a $4.5 \mathrm{~mm}$ sprue diameter and the wax patterns belonging to groups II and IV were sprued with a $2.5 \mathrm{~mm}$ sprue diameter at $45^{\circ}$ angle. A reservoir was placed at $2 \mathrm{~mm}$ from the sprue ends. The entire assembly was attached to the wax crucible former such that it was $6 \mathrm{~mm}$ away from the ring end and each assembly were invested separately.

In the metal ring casting technique, the ring was lined with wet cellulose ring liner and the investment was conventionally allowed to bench set for 1 hour. However, in the ringless casting technique, each of the ring was left in the pressure pot at 1.5 psi for 5 minutes and after 10 minutes of initial setting, the plastic rings were removed and allowed to bench set for an hour.

The molds were placed in the burn out furnace at $230^{\circ}$ till it reached $950^{\circ}$ at which it was maintained for 15 minutes to ensure complete wax burn out. The molds were then cast with two nickel-chromium pellets. The retrieved castings were divested with sandblasting with 50 microns aluminum oxide particles and then ultrasonically cleaned. The sprues were removed and a "blind operator" placed the castings on the master die using only finger pressure. In case, the internal surface had some minor defects, they were removed with a diamond coated round bur.

\section{MEASUREMENTS AND STATISTICAL ANALYSIS}

The metal castings were seated on the metal die and the accuracy of fit was evaluated by measuring the gap between the finish line and the margins of the casting on three predetermined specific sites with the use of Mitutoyo toolmaker microscope under $\times 15$ magnification. Statistical analysis was executed using IBM Statistical Package for the Social Sciences statistic 20 (Table 2). The mean vertical discrepancy for each group was analyzed (Graph 1) by a two-way analysis of variance (ANOVA) (Table 3) followed by independent $\mathrm{t}$-test to analyze the interaction (Table 4).

\section{RESULTS}

The values from two-way ANOVA indicated that there was statistical significance in the type of ring system

Table 2: Descriptive analysis

\begin{tabular}{llll}
\hline $\begin{array}{l}\text { Type of } \\
\text { ring }\end{array}$ & Sprue diameter $(\mathrm{mm})$ & Mean $\pm \mathrm{SD}(\mathrm{mm})$ & $n$ \\
\hline Ring & 2.5 & $0.22653 \pm 0.091452$ & 10 \\
& 4.5 & $0.30277 \pm 0.098573$ & 10 \\
& Total & $0.26465 \pm 0.100467$ & 20 \\
Ringless & 2.5 & $0.17150 \pm 0.089493$ & 10 \\
& 4.5 & $0.12000 \pm 0.038968$ & 10 \\
& Total & $0.14575 \pm 0.072187$ & 20 \\
\hline SD: Standard deviation & &
\end{tabular}


An in vitro Comparative Study to evaluate the Marginal Fit of Castings using Ring and Ringless Casting Techniques

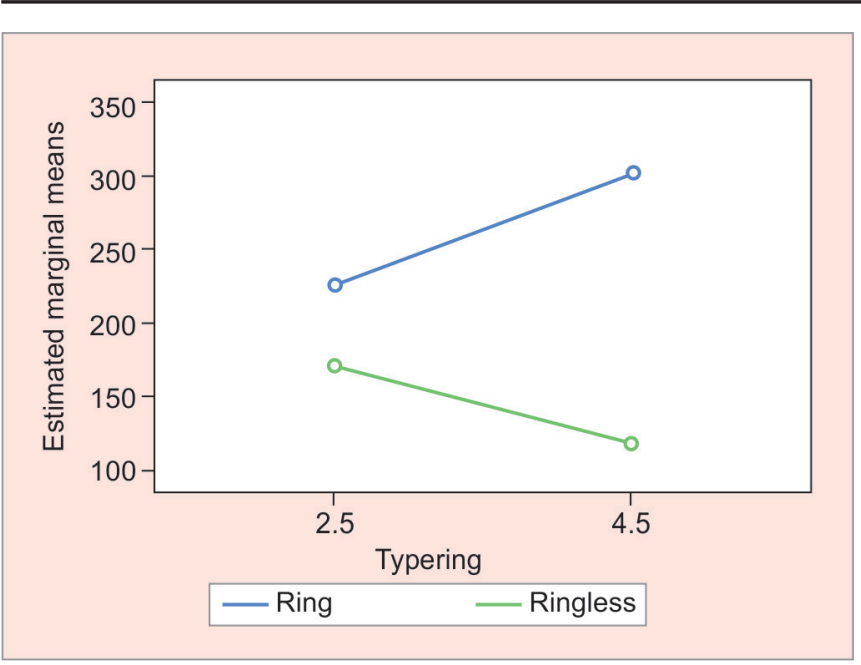

Graph 1: Mean vertical discrepancies of the groups

used and also an interaction between the type of the ring and the sprue diameter. The ringless casting technique produced significantly less vertical discrepancy in comparison to the metal ring casting technique (groups I and II: $0.264 \pm 0.100 \mathrm{~mm}$ and groups III and IV: $0.145 \pm$ $0.072 \mathrm{~mm}$ ). The independent $\mathrm{t}$-test analysis showed that there was statistical significance when a $4.5 \mathrm{~mm}$ sprue diameter was used in the ringless casting technique.

\section{DISCUSSION}

The minimum estimate of marginal discrepancy of fixed restorations has been an issue of contention. Holmes et a $1^{19}$ have defined the internal gap as the measurement between the axial wall of the prepared tooth and the internal surface of the casting, while the same measurement at the margin was called the "marginal gap." The American Dental Association specification number 8 has denoted that the thickness of luting cement for a fixed crown should not surpass $25 \mu \mathrm{m}$ for type I luting agent or $40 \mu \mathrm{m}$ for type II luting agent. These values of marginal openings are rarely achieved. ${ }^{20}$ Henceforward, McLean and Von Fraunhofer ${ }^{21}$ argued and accomplished a 120 to $150 \mu \mathrm{m}$ opening after cementation could be deliberated as an acceptable marginal gap range.

The accuracy of casting is influenced by various factors, but there is no clear evidence in literature to which variable should be controlled that provides consistently an improved marginal fit of dental castings to prevent microleakage and secondary caries development. ${ }^{7,22-25}$

The conventional metal ring casting technique has been an unfailing technique that has produced clinically acceptable dental prosthesis. However, due to definite restriction of setting and thermal expansion of the investment material by the metal ring coupled with the solidification shrinkage of alloy and uneven thermal expansion of the metal casting ring leads to undersized

\begin{tabular}{llllll}
\multicolumn{5}{c}{ Table 3: Two-way ANOVA } \\
\hline & Type III sum & \multicolumn{4}{c}{ Mean } \\
of squares & df & square & F-value & Significant \\
Source & 0.141 & 1 & 0.141 & 20.483 & $<0.001$ \\
\hline Type of ring & 0.002 & 1 & 0.002 & 0.222 & 0.641 \\
Sprue diameter & 0.002 & 1 & 0.041 & 5.910 & 0.020 \\
$\begin{array}{l}\text { Type of ring* } \\
\text { sprue diameter }\end{array}$ & 0.041 & & & & \\
Corrected total & 0.432 & 39 & & & \\
\hline
\end{tabular}

Table 4: Independent t-test in groups I and III

\begin{tabular}{llllc}
\hline & Type of ring & $n$ & Mean \pm SD $(\mathrm{mm})$ & $p$-value \\
\hline Average & Ring & 10 & $0.30277 \pm 0.098573$ & $<0.001$ \\
& Ringless & 10 & $0.12000 \pm 0.038968$ & \\
\hline
\end{tabular}

SD: Standard deviation

castings with increased vertical marginal gaps. ${ }^{8-12}$ Hence, with the use of the ringless casting technique, the above limitations could be eliminated..$^{13,14}$

In an in vitro study investigated in 2000, Lombardas et $\mathrm{al}^{6}$ stated that ringless casting technique produced less vertical discrepancy (181 $\pm 71 \mu \mathrm{m}$ with Bego) in comparison to the castings produced with conventional metal ring technique ( $290 \pm 87 \mu \mathrm{m}$ with whip-mix and $291 \pm 88 \mu \mathrm{m}$ with Bego), denoting that both the methods were within the clinical acceptable range, nonetheless the ringless technique being appreciably more accurate method.

In 2014, Prasad et $\mathrm{al}^{26}$ evaluated the combination of accelerated wax elimination technique with ringless casting technique in comparison with the conventional wax eliminated and metal ring casting technique. The results were again in bias of ringless casting technique $(76.98 \pm 7.59 \mu \mathrm{m})$ whether conventionally wax eliminated or accelerated wax eliminated in the production of less vertical discrepancies.

In this study, the resultant mean vertical discrepancies were similar to the above studies, proving that due to isotropic expansion of the investment material in the ringless casting technique the marginal adaptation of metal castings were improved. The observed mean of marginal discrepancies in ringless group (groups III and IV) was $0.145 \pm 0.072 \mathrm{~mm}$ and in the metal ring was $0.264 \pm 0.100 \mathrm{~mm}$ (groups I and II).

The primary function of sprue is to form a channel through which the molten metal can flow and fill the mold space. The diameter of the sprue is considered to be one of the crucial variable that influences the castings marginal adaptation. In this experiment, two diameters were considered thicker ${ }^{15}$ than the ordinarily formed wax patterns, to evaluate its effect on the marginal discrepancy of the nickel-chromium alloy castings.

The obtained results were plotted on profile graph and it can be inferred that in the metal ring groups with increase in the diameter of the sprue the marginal 
discrepancy increased (group I > group II). However, in the ringless groups, with increase in the diameter of the sprue the marginal discrepancy decreased (group IV $>$ group III).

Overall, the $4.5 \mathrm{~mm}$ diameter gave the least marginal discrepancy in the ringless group (group I > group II > group IV > group III).

Thus, along with an uniform setting and thermal expansion of the phosphate bonded investment material in the ringless casting technique, a larger sprue diameter would allow an easier and unobstructed channel for the molten metal to fill in the mold space uniformly. This was observed in group III, with the larger sprue diameter having the least mean vertical discrepancy of $0.12000 \mathrm{~mm}$ in relation to group IV of smaller sprue diameter with a mean discrepancy of $0.17150 \mathrm{~mm}$. Altogether, due to the unrestricted expansion of the ringless casting technique, the metal castings produced through this method produced the least vertical discrepancies.

However, in the metal ring groups due to a nonuniform expansion of the investment and the metal ring, a larger sprue would cause greater solidification shrinkage causing greater distortion in contrast with a smaller sprue diameter. Hence, in group II, a lesser mean vertical discrepancy of $0.22653 \mathrm{~mm}$ with the smaller diameter was observed and in group I with $4.5 \mathrm{~mm}$ diameter, a larger vertical discrepancy $0.30277 \mathrm{~mm}$ was observed.

Thus, from this study, the marginal fit of metal castings was much more accurate in the ringless casting technique groups which are consistent to the results achieved in other similar studies. The sprue diameter also played a major role in the marginal discrepancy with differing results in both of the casting techniques. A larger sprue diameter allowed the molten metal to have smooth path to fill the mold space in an investment material, i.e., capable to expand uniformly and compensate for the solidification shrinkage of the alloy. However, the same larger sprue diameter in metal ring casting technique would cause a larger spot of molten metal that would solidify last and, therefore, result in greater vertical discrepancies.

The main limitations of the study are the significance of the die spacer, expansion of die stone, tooth geometry, etc., which also have effects in the accuracy of casting in metal restorations. Hence, further investigations should be performed interlinking all of the possible variables to denote that the ringless casting technique is better technique than the metal ring casting technique.

\section{CONCLUSION}

Within the limitations of the study, following conclusions can be drawn:

- The ringless casting technique has an isotropic expansion of the investment material and hence, is capable to compensate the solidification shrinkage of the alloy and, therefore, the least discrepancy was observed in the ringless casting groups.

- In the ringless group, the larger sprue diameter showed the least discrepancy followed by the thinner sprue. However, the mean was not significantly different and well within the clinical range. Hence, both of the diameters can be utilized when using the ringless casting technique.

- Overall, the metal ring casting groups produced greater marginal discrepancy of the metal castings. However, the thinner diameter showed lesser discrepancy in comparison to the larger sprue diameter. This can insinuated that because of larger spot of molten metal being solidified last in the larger sprue diameter, it could result in greater localized shrinkage and cause greater vertical discrepancies.

\section{REFERENCES}

1. Foster LV. Failed conventional bridge work from general dental practice: clinical aspects and treatment needs of 142 cases. Br Dent J 1990 Mar;168(5):199-201.

2. Bader JD, Rozier RG, McFall WT Jr, Ramsey DL. Effect of crown margins on periodontal conditions in regularly attending patients. J Prosthet Dent 1991 Jan;65(1):75-79.

3. Knoernschild KL, Campbell SD. Periodontal tissue responses after insertion of artificial crowns and fixed partial dentures. J Prosthet Dent 2000 Nov;84(5):492-498.

4. Goodacre CJ, Bernal G, Rungcharassaeng K, Kan JY. Clinical complications in fixed prosthodontics. J Prosthet Dent 2003 Jul;90(1):31-41.

5. Johnson A, Winstanley RB. The evaluation of factors affecting the castability of metal ceramic alloy-investment combinations. Int J Prosthodont 1996 Jan-Feb;9(1):74-78.

6. Lombardas P, Carbunaru A, McAlarney ME, Toothaker RW. Dimensional accuracy of castings produced with ringless and metal ring investment systems. J Prosthet Dent 2000 Jul;84(1):27-31.

7. Johnson A. The effect of sprue design and alloy type on the fit of three-unit metal/ceramic bridges. Eur J Prosthodont Restor Dent 1995 Dec;3(6):241-245.

8. Lloyd CH, Yearn JA, Cowper GA, Blavier J, Vanderdonckt M. Measurement of the setting expansion of phosphate-bonded investment materials. Part I - development of the casting-ring test. J Oral Rehabil 2004 Jul;31(7):695-702.

9. Morey EF. Dimensional accuracy of small gold alloy castings. Part 4. The casting ring and ring liners. Aust Dent J 1992;37(2):91-97.

10. Del Castillo R, ErcoliC, Graser GN, Tallents RH, Moss ME. Effect of ring liner and casting ring temperature on the dimension of cast posts. J Prosthet Dent 2000 Jul;84(1):32-37.

11. Rudd, K.; Morrow, R.; Eissmann, H. Removable partial dentures: investment, burn out and casting. In: Dental laboratory procedures. Vol. III. St. Louis: CV Mosby; 1981. p. 293-320.

12. McGivney, GP.; Castleberry, DJ. McCracken's removable partial prosthodontics: laboratory procedures. St. Louis: CV Mosby; 1989.

13. Dern WM, Hinman RW, Hesby RA, Pelleu GB Jr. Effect of a two-step ringless investment technique on alloy castability. J Prosthet Dent 1985 Jun;53(6):874-876. 
14. Carr AB, Stewart RB. Full-arch implant framework casting accuracy: preliminary in-vitro observation for in vivo testing. J Prosthodont 1993 Mar;2(1):2-8.

15. Anusavice JK. Phillip's science of dental materials. 11th ed. St. Louis: Elsevier; 2003.

16. Strickland WD, Sturdevant CM. Porosity in the full cast crown. J Am Dent Assoc 1959;58(4):69-78.

17. Schilling ER, Miller BH, Woody RD, Miller AW3rd, Nunn ME. Marginal gap of crowns made with a phosphate-bonded investment and accelerated casting method. J Prosthet Dent 1999 Feb;81(2):129-134.

18. Leal MB, Paulino SM, Pagnano VO, Bezzon OL. Influence of investment type and sprue number on the casting accuracy of titanium crown margins. J Prosthet Dent 2006 Jan;95(1):42-49.

19. Holmes JR, Bayne SC, Holland GA, Sulik WD. Considerations in measurement of marginal fit. J Prosthet Dent 1989 Oct;62(4):405-408.

20. American Dental Association. ANSI/ADA specification no. 8 for zinc phosphate cement. In: Guide to dental materials and devices. 5th ed. Chicago: American Dental Association; 1970-1971.
21. McLean JW, von Fraunhofer JA. The estimation of cement film thickness by an in vivo technique. Br Dent J 1971 Aug;131(3):107-111.

22. Gravelis JR, Morency JD, Riley ED, Sozio RB. The effect of various finish line preparations on the marginal seal and occlusal seat of full crown preparations. J Prosthet Dent 2004 Jul;92(1):1-7.

23. Nesse H, Ulstein DMA, Vaage MM, Øilo M. Internal and marginal fit of cobalt-chromium fixed dental prostheses fabricated with 3 different techniques. J Prosthet Dent 2015 Nov;114(5):686-692.

24. Gelbard S, Aoskar Y, Zalkind M, Stern N. Effect of impression materials and techniques on the marginal fit of metal castings. J Prosthet Dent 1994 Jan;71(1):1-6.

25. Piemjai M. Effect of seating force, margin design, and cement on marginal seal and retention of complete metal crowns. Int J Prosthodont 2001 Sep-Oct;14(5):412-416.

26. Prasad R, Al-Keraif AA, Kathuria N, Gandhi PV, Bhide SV. Accuracy of ringless casting and accelerated wax-elimination technique: a comparative in-vitro study. J Prosthodont 2014 Feb;23(2):157-162. 